\title{
Substantial recovery of a masked visual target and its theoretical interpretation
}

\author{
WILLIAM N. DEMBER, MARVIN SCHWARTZ, and MICHAEL KOCAK \\ University of Cincinnati, Cincinnati, Ohio 45221
}

\begin{abstract}
Previous demonstrations of the perceptual recovery of a retroactively masked visual target by a subsequent masking stimulus have not yet been alluded to in theories of backward masking, perhaps because such data seem inconsistent with current theory and because the effects reported so far have been relatively small. We report here a set of conditions that yield substantial recovery and also suggest an account of recovery derived from an interpretation of the masking theory of Breitmeyer and Ganz.
\end{abstract}

The perception of a target stimulus can be impaired by a subsequent "masking" stimulus. Theories of masking have set as their main task the development of a plausible account of how this retroactive effect ("backward masking") of one stimulus on another might take place. Although no single theory seems yet to have provided a convincing explanation of all the findings associated with empirical research on backward masking, recent theories based on postulated neurophysiological processes (e.g., Breitmeyer \& Ganz, 1976; Weisstein, Ozog, \& Szoc, 1975) have enjoyed considerable success. However, as Dember (Note 1) has pointed out, even the best of the masking theories may have one serious flaw in that they do too effective a job in obliterating the target stimulus. This seems to pose a serious problem in light of evidence (Dember \& Purcell, 1967; Robinson, 1966) that it is possible to recover a masked target by presenting a second masking stimulus following the first mask. One reasonable implication of recovery is that masking does not entirely remove the representation of the target from the visual system; rather, something must remain after masking to provide the basis for recovery of the target upon presentation of the second masking stimulus.

To the extent that target recovery is a genuine phenomenon, masking theories will have to deal with it in some manner. So far, data demonstrating recovery have largely been either ignored or dismissed as artifactual. For example, neither Breitmeyer and Ganz (1976) nor Weisstein et al. (1976) make reference to the original experiments by Robinson and by Dember and Purcell, or to subsequent demonstrations of target recovery (e.g., Robinson, 1968). And Schurman and Eriksen (1969) question the replicability of the Robinson data, attributing his results to various response artifacts.

Requests for reprints should be sent to William N. Dember, Department of Psychology, University of Cincinnati, Cincinnati, Ohio 45221.
Another reason why target recovery does not yet play a significant role in masking theories may be that the absolute extent of recovery in experiments reported so far seems too small to take seriously. For example, in one of the two experiments reported by Dember and Purcell (1967), mean percent correct target recognition rose from about $56 \%$ in the standard singlemask condition to about $65 \%$ in the double-mask (recovery) condition, a difference, though statistically significant, of only about $9 \%$. Recovery might be given more theoretical weight if data revealing a greater effect could be presented. In this paper, we provide such data, and we also show how recovery might be explained within the Breitmeyer and Ganz (1976) theory.

The present experiment was conducted as a follow-up of the psychophysical portion of a psychophysiological study by Schwartz, Whittier, and Schweitzer (Note 2) that attempted to relate cortical evoked responses to perceptual performance under nonmasking, masking, and recovery conditions. The design of that experiment closely followed Dember and Purcell (1967), but the stimuli as well as the temporal and luminance parameters were quite different. The psychophysical aspect of the Schwartz et al. study was ancillary to its main purpose; however, the extent of recovery exhibited by the three sophisticated subjects was so striking $(100 \%$ in one case) as to call for formal replication using a larger number of subjects, and subjects who were naive about the expected outcome.

\section{METHOD}

\section{Subjects}

The subjects were 16 volunteers from introductory psychology classes, 8 male and 8 female. Ages ranged from 17 to 25 years, with a mean of 20.3. All subjects had normal or corrected-to-normal vision.

\section{Apparatus}

The stimuli were presented using an Iconix tachistoscope and were back illuminated. The target stimuli were the black letters $\mathrm{p}, \mathrm{d}, \mathrm{b}$, or $\mathrm{q}$ centered on white disks $40 \mathrm{~min}$ in diameter. Each letter was $29 \mathrm{~min}$ in height, $22 \mathrm{~min}$ in width, and with a strip width of $7 \mathrm{~min}$. Mask 1 was a white disk, $40 \mathrm{~min}$ in 
diameter, with black bars similar to those used in constructing the letters randomly placed on its surface. Mask 2 was a homogeneous white disk subtending an angle of $1 \mathrm{deg} 20 \mathrm{~min}$. The fixation field was dark except for four small red fixation points arranged in a $Y$ shape. Targets were illuminated at $7 \mathrm{fL}$, Mask 1 at $2.5 \mathrm{fL}$, and Mask 2 at $15 \mathrm{fL}$. Viewing was binocular; all stimuli were presented to the fovea.

\section{Procedure}

After a 5-min dark-adaptation period, each subject was exposed to 40 practice trials, 10 of each of 4 conditions. The study consisted of 50 trials/condition divided into two 12-trial and two 13-trial runs. Order of presentation of the stimuli and of the conditions was randomized. The presentation of stimuli was self-paced, with the subject initiating each trial by pressing a hand-held pushbutton after a ready signal from the experimenter. Throughout the experiment, the subject's only task was to indicate which target letter had been presented.

The four conditions were: $\mathrm{T}$, target alone; $\mathrm{T}+1$, target followed by Mask 1; $\mathrm{T}+2$, target followed by Mask 2; $\mathrm{T}+1+2$, target followed by Mask 1 followed by Mask 2 . Target duration was $10 \mathrm{msec}$. The interstimulus interval between the target and Mask 1 was $7 \mathrm{msec}$. The duration of Mask 1 was $20 \mathrm{msec}$, and the interval between it and Mask 2 was $10 \mathrm{msec}$. The duration of Mask 2 was $30 \mathrm{msec}$. Under the $\mathrm{T}+2$ condition, the interstimulus interval between the target and Mask 2 was the same as in the $\mathrm{T}+1+2$ condition (i.e., $37 \mathrm{~m} \mathrm{sec}$ ).

\section{RESULTS}

Percent correct target recognition for each subject in each condition is given in Table 1. There was a significant masking effect $[\mathrm{t}(15)=22.38, \mathrm{p}<.001]$ in the $T+1$ condition, but, as expected, virtually no masking in $T+2$. There was also a significant difference in performance between $\mathrm{T}+1$ and $\mathrm{T}+1+2[\mathrm{t}(15)=12.64$, $\mathrm{p}<.001]$ in a direction and of a magnitude indicative of a substantial recovery effect. Table 1 shows that in the $T+1+2$ condition, 7 of the 16 subjects were correct

Table 1

Percent Correct Target Recognition

\begin{tabular}{ccccc}
\hline Subject & $\mathrm{T}$ & $\mathrm{T}+1$ & $\mathrm{~T}+2$ & $\mathrm{~T}+1+2$ \\
\hline 1 & 100 & 56 & 100 & 98 \\
2 & 100 & 44 & 100 & 70 \\
3 & 100 & 34 & 100 & 98 \\
4 & 100 & 28 & 100 & 76 \\
5 & 100 & 30 & 96 & 84 \\
6 & 100 & 56 & 100 & 100 \\
7 & 100 & 32 & 100 & 84 \\
8 & 100 & 46 & 100 & 78 \\
9 & 100 & 46 & 100 & 92 \\
10 & 100 & 56 & 96 & 92 \\
11 & 100 & 46 & 100 & 82 \\
12 & 100 & 42 & 98 & 80 \\
13 & 100 & 42 & 100 & 92 \\
14 & 100 & 60 & 100 & 94 \\
15 & 100 & 32 & 100 & 42 \\
16 & 100 & 44 & 100 & 76 \\
Mean & 100 & 43.4 & 99.4 & 83.6 \\
SD & 0 & 10.3 & 1.4 & 14.3 \\
\hline
\end{tabular}

Note-T = target alone; $T+1=$ target followed by Mask 1; $T+2=$ target followed by Mask $2 ; T+1+2=$ target followed by Mask 1 followed by Mask 2. on at least $90 \%$ of the trials. The mean performance level over all subjects shifted from $43.4 \%$ in $\mathrm{T}+1$ to $83.6 \%$ in $\mathrm{T}+1+2$.

\section{DISCUSSION}

Since the present experiment differed in several ways from the Dember and Purcell (1967) study on which it was modeled, it is not possible to identify the factors responsible for the considerable increase in the extent of target recovery. That can be accomplished with further experimentation.

In any event, the present results demonstrate target recovery of substantial magnitude. Moreover, the psychophysical task (letter recognition) is not one to which Schurman and Eriksen's (1969) criticisms of Robinson's (1966) data are applicable.

Although it has been our assumption that target recovery poses a serious problem for most current masking theories, there may be a way of incorporating our data into a complex theory such as that of Breitmeyer and Ganz (1976). In particular, Breitmeyer and Ganz posit two types of masking, $A$ and B, corresponding to the two types of "masking function": those where recognition accuracy is a monotonic function of the time between target and mask onsets (stimulus onset asynchrony, or SOA) and those where the function is $U$ shaped. According to Breitmeyer and Ganz, Type A masking occurs when conditions are such that target recognition is impaired through the mixing or integration of the excitatory neural activity in "sustained channels," which process information about medium-to-high spatial frequency components in both target and mask stimuli.Type B masking occurs as a result of the inhibition of sustained channel activity associated with the target by "transient channel" activity associated with the mask. Transient channel activity is triggered by stimulus onset, and it has a shorter latency than sustained channel activity.

Our results might fit such a theory if it can be assumed that (1) the masking effect obtained in $T+1$ is carried primarily by integration of the sustained channel activities associated with both target and mask; and (2) the transient channel activity associated with Mask 2 inhibits the sustained channel activity associated with Mask 1 before the latter can be integrated with the sustained channel activity of the target. In other words, target recovery could be understood within the Breitmeyer and Ganz (1976) theory if the $T+1$ condition is conducive to Type A masking and the $\mathrm{T}+1+2$ condition to masking (of Mask 1 by Mask 2) of Type B. In our experiment, the subject's task, letter recognition, and the nature of the target and masking stimuli do appear to meet the Breitmeyer and Ganz criteria. However, one aspect of our results may seem puzzling: Why, with an interval of only $37 \mathrm{msec}$ between Mask 2 and the target (a SOA of $47 \mathrm{msec}$ ), was there no masking evident in $\mathrm{T}+2$ ? That is, why should the transient activity generated by Mask 2 have been so effective in inhibiting the sustained activity associated with Mask 1, but so ineffective against the target, when in both cases conditions should have been conducive to a U-shaped masking function? That problem can be handled by reference to the observation by Breitmeyer and Ganz that the sustained channel processing of the information in a single-element stimulus proceeds much more rapidly than does the processing of a multielement stimulus. If our target stimulus (a simple, single letter) fits the former description and Mask 1 (random bars) the latter, then we can see how Mask 2 might be capable of inhibiting the processing of Mask 1 without also impairing recognition of the target stimulus.

Much to our own surprise, we come to the conclusion that rather than embarrassing the Breitmeyer and Ganz (1976) theory, target recovery can be viewed as providing a nonobvious confirmation of the theory. Be that as it may, the present data demonstrate that target recovery is real and that, under proper conditions, it can be quite substantial. 


\section{REFERENCE NOTES}

1. Dember, W. N. Looking backward. Presidential address to the Midwestern Psychological Association, Chicago, Ill: May 1976.

2. Schwartz, M., Whittier, O., \& Schweitzer, P. Evoked responses to retroactively masked stimuli. Unpublished manuscript.

\section{REFERENCES}

Breitmeyer, B. G., \& GANz, L. Implications of sustained and transient channels for theories of visual pattern masking, saccadic suppression, and information processing. Psychological Review, 1976, 83, 1-36.

Dember, W. N., \& Purcell, D. G. Recovery of masked visual targets by inhibition of the masking stimulus. Science, 1967, 157, 1335-1336.
Robinson, D. N. Disinhibition of visually masked stimuli. Science, 1966, 154, 157-158.

Robinson, D. N. Visual disinhibition with binocular and interocular presentations. Journal of the Optical Society of America, 1968, 58, 254-257.

Schurman, D. L., \& Eriksen, C. W. Summation and interaction of successive masking stimuli in visual perception. American Journal of Psychology, 1969, 82, 320-332.

Weisstein, N., Ozog, G., \& Szoc, R. A comparison and elaboration of two models of metacontrast. Psychological Review, 1975, 82, 325-343.

(Received for publication January 14, 1978.) 